\title{
Notas sobre Filosofia, Linguagem e Antropologia em Investigações Filosóficas de Ludwig Wittgenstein
}

\author{
Notes about Philosophy, Language and Anthropology in Ludwig \\ Wittgenstein's Philosophical Investigations \\ LEANDRO SOUSA COSTA ${ }^{1}$ \\ LEONARDO NUNES CAMARGO²
}

\begin{abstract}
Resumo: As considerações que faremos neste artigo são pautadas na possibilidade de discutir um enfoque antropológico na filosofia das Investigações Filosóficas de Ludwig Wittgenstein. O texto se divide em duas partes: a primeira apresenta a concepção de linguagem no Tractatus Logico-Philosophicus que é a concepção tradicional de linguagem na filosofia no ocidente. Tratamos especificamente sobre as categorias estruturais do mundo, a teoria da figuração e a doutrina do isomorfismo. A segunda apresenta o texto de Investigações no intuito de mostrar que a linguagem do cotidiano é uma linguagem entendida numa perspectiva pragmática pois é expressa a partir de objetos, gestos e ações concretas. Os contextos práticos de ação do homem são fundamentais para entender sua nova abordagem sobre a linguagem, uma vez que defendemos ser o enfoque antropológico engendrado a partir de sua abordagem pragmática da linguagem.
\end{abstract}

Palavras-chave: Filosofia. Linguagem. Antropologia. Wittgenstein.

Abstract: The comments hereby made are based on the possibility of discussing an anthropological scope in Ludwig Wittgenstein's Philosophical Investigations. The essay is twofold: the first part presents the concept of language found in the author's Tractatus Logico-Philosophicus, which comes from Western Philosophy. The discussion will delve deeper into world structuring categories, a theory of figuration and a proposition of isomorphism. The second part rests upon Investigations to show that everyday language is analysed from a pragmatic perspective, as it is expressed by objects, gestures and concrete actions. The tactical settings on which human activity develops are key to understand his anew approach to language, since we stand by the idea of an anthropological bias underlying his pragmatic view of language.

Keywords: Philosophy. Language. Anthropology. Wittgenstein.

\section{Introdução}

Somos, quando filosofamos, como seres selvagens, homens primitivos que ouvem o modo de expressão de homens civilizados, interpretam-no mal e tiram as mais estranhas conclusões de sua interpretação (Ludwig Wittgenstein - Investigações Filosóficas, § 194).

A discussão que faremos neste texto é pautada na possibilidade de defender

\footnotetext{
${ }^{1}$ Professor da Universidade Estadual do Paraná e Doutorando em Filosofia pela PUC-PR. E-mail: leandro_kallas@hotmail.com

${ }^{2}$ Mestrando em Filosofia pela PUC-PR. E-mail: leonardo_bigmusic@yahoo.com.br
} 
uma reflexão antropológica na filosofia de Investigações Filosóficas ${ }^{3}$ (1953) de Ludwig Wittgenstein. A nossa tentativa é a de explicitar de que modo a pragmática linguística é possuidora de notas que caracterizam, em certa medida, uma virada antropológica em sua filosofia da linguagem. Em sua fase tardia o filósofo empreende esforço que atenta contra qualquer forma de essencialismo e conceitualização. A virada antropológica que nos referimos não caracteriza uma ciência no pensamento do austríaco, mas, antes, um particular modo de conceber as atividades do cotidiano que dizem respeito às ações práticas do homem. Nossa tarefa concentrar-se-á em explicitar o deslocamento da concepção sintático-semântica à concepção pragmática, fornecendo indícios de que a perspectiva antropológica se torna evidente a partir desta última e pode ser pensada a partir de temas tratados na obra Investigações Filosóficas.

O texto se divide em duas partes: a primeira apresenta, brevemente, a concepção de linguagem no Tractatus Logico-Philosophicus ${ }^{4}$ (1921) que incorpora a concepção tradicional da filosofia no ocidente ${ }^{5}$. A segunda apresenta o texto de Investigações no intuito de mostrar que a linguagem é entendida numa perspectiva pragmática, expressa a partir de objetos, gestos e ações concretas. Isto é, precisamos recorrer aos usos, às nossas práticas linguísticas para pensar o significado ${ }^{6}$ das expressões. Não obstante, neste último caso, o autor em sua filosofia, deixa entrever uma perspectiva antropológica ao olhar para o homem em sua situação de cotidiano que estabelece vínculos práticos de ação, apropria-se de hábitos e costumes, explicitado em suas manifestações linguísticas, e constrói sua subjetividade coletivamente.

\section{A virada antropológica wittgensteiniana: do isomorfismo aos jogos de linguagem}

Na passagem do século XIX para o século XX, percebemos um deslocamento significativo no modus operandi da filosofia que, em várias correntes e a partir de diferentes pontos de partida, passam a se preocupar com uma teoria do significado. Apesar dos inúmeros desdobramentos e desenvolvimentos numa série de doutrinas, destacamos, em linhas gerais, algumas delas, tais como a semiótica de Pierce, a hermenêutica, formulada por Dilthey, Gadamer, Vattimo, entre outros e o estruturalismo, o empirismo lógico, a filosofia analítica de Moore e Russell, a filosofia das formas simbólicas de Cassirer 7 . O cenário que se apresenta, em certa medida, é o

\footnotetext{
${ }^{3}$ Ao referenciarmos a obra Investigações Filosóficas, usaremos a abreviatura "IF".

${ }^{4}$ Ao referenciarmos a obra Tractatus Logico-Philosophicus, usaremos a abreviatura "TLP".

5 Adotamos os termos "concepção tradicional de linguagem na filosofia do ocidente" ou "semântica clássica" para designar as concepções formalistas de linguagem, que caracterizam o significado a partir da noção de condições de verdade e não consideram a linguagem em uso. Alguns filósofos dessa corrente são: Gotlob Frege, Bertrand Russell, o primeiro Wittgenstein e o positivismo lógico.

${ }^{6}$ Em um sentido amplo, entendemos por "significado" o caráter representacional dos signos linguísticos.

${ }^{7}$ Tendo em vista que discutir outras abordagens metodológicas para a filosofia do século XIX-XX não é nosso objetivo aqui, sugerimos, para maiores elucidações, o texto STEGMULLER, Wolfgang. A filosofia
} 
de tentar superar os impasses da tradição moderna com a ferramenta da linguagem.

A esse deslocamento damos o nome de virada linguística. Se por um lado temos o paradigma dos estudos da linguagem formulados pela lógica-matemática que usam do recurso da construção de sistemas formais, notações simbólicas, métodos quantitativos, cálculos matemáticos, mesmo nas ciências humanas, por outro temos o paradigma da linguagem como um sistema simbólico que viabiliza a comunicação humana e constitui suas experiências sociais e culturais. É segundo estas perspectivas que devemos tomar, a título de consideração, as disciplinas que tem como objeto de estudo a linguagem em seus diferentes aspectos pois elas constituem a base metodológicas e teórica das ciências em geral. Sendo assim, é possível pensar, em linhas gerais, que a primeira abordagem, de cunho analítico-logicista, objetivava fundamentar epistemologicamente as ciências da natureza ${ }^{8}$ e a segunda fundamenta as interpretações culturalistas.

Tendo em vista esse quadro teórico e a partir deste contexto de preocupações que, segundo Wolfgang Stegmuller (Cf. STEGMULLER, 2012), Wittgenstein se constitui como um dos filósofos mais influentes desde a segunda década do século $X X$. Tamanha é a influência de sua filosofia que duas correntes de pensamento estão ligadas a ele, o empirismo lógico ou neopositivismo do Círculo de Viena (que se liga à filosofia do Tractatus) e a filosofia da linguagem ordinária (ligada às Investigações Filosóficas). Apesar das diferenças estruturais entre a primeira e a segunda fase do seu pensamento, podemos ver, pelo menos, uma continuidade temática quando do seu interesse pelo significado das expressões linguísticas.

Além de mostrar a relação linguagem, pensamento e mundo, sua intenção fundamental no Tractatus é estabelecer com clareza as fronteiras entre o que racionalmente pode ser dito e o disparate que deve ser evitado. A linguagem tem uma função designativa-intrumentalista-comunicativa que é, por outros termos, a concepção de linguagem no ocidente. A tese fundamental de Wittgenstein é a de que linguagem figura o mundo sobre o qual ela fala e a respeito do qual nos informa. As categorias estruturais do mundo serão, para ele, os fatos (subsistir de estados de coisa) (Cf. TLP, 2), os estados de coisa (determinado tipo de associação de coisas) (Cf. TLP, 2.01) e as coisas (parte inanalisável da realidade) (Cf. TLP, 2.02), onde "o mundo" se constituirá como "a totalidade dos fatos, não das coisas" (TLP, 1.1), como sustenta o filósofo no início da obra. É com a teoria da figuração que a filosofia do Tractatus procura estabelecer de que modo a linguagem espelha o mundo (Cf. TLP, 2.11; 2.12), e a doutrina do isomorfismo esclarece que a identidade estrutural entre estes dois polos permite tal correspondência (Cf. TLP, 4.05) que é, em outras palavras, a forma lógica. Neste sentido, o autor afirma que, “a figuração pode afigurar toda realidade

contemporânea. Introdução crítica 2a ed. Rio de Janeiro: Forense Universitária, 2012.

${ }^{8}$ Aqui nos referimos às ciências tradicionais (física, química, matemática), bem como àquelas que estavam nascendo em meados do século XX. 
cuja forma ela tenha" (TLP 2.171).

Podemos notar que a semântica, na obra da primeira fase do seu pensamento, postulou predicados e sentenças não como objetos, mas como relações e, portanto, como fatos. Haveria, aqui, uma ontologia formal na concepção de mundo. Além de designar e exprimir, a linguagem é correspondência da estrutura categorial das expressões à estrutura categorial da realidade. A importância da tese semântica de Wittgenstein se manifesta pela tematização e pela explicitação dos pressupostos ontológicos da semântica tradicional, bem como a tese da correspondência entre linguagem e realidade.

Sua segunda filosofia se desenvolve a partir de uma crítica radical à tradição filosófica ocidental da linguagem, modelo essencialista levado às últimas consequências no Tractatus. Mesmo a questão sobre o significado da linguagem permanecendo, o pensamento dessa fase encontra-se em oposição com o da primeira. O cerne da reflexão linguística deixa de ser a linguagem ideal para se tornar a situação na qual o homem usa sua linguagem, "a linguagem do cotidiano" (IF, § 120); então o único meio de saber o que é a linguagem é olhando seus diferentes usos.

A filosofia, no contexto do pensamento tardio wittgensteiniano, especialmente em Investigações Filosóficas, é entendida não como uma disciplina que fornece explicações, teses ou determina hipóteses acerca da realidade. Tampouco determina fundamentos seguros para a realidade. O papel, se é que ele existe, da filosofia, seria o de o de esclarecer de forma descritiva o uso que fazemos da linguagem. É uma luta, nas palavras do filósofo, contra o enfeitiçamento que o descuido no uso da linguagem provoca em nosso intelecto. Devemos olhar, portanto, os contextos de uso efetivo da linguagem, onde os sujeitos produzem conhecimento, história e cultura.

Neste sentido, homem e conhecimento são situados no processo de interação social e a comunidade tem um papel na constituição do conhecimento e da linguagem humana. Esse meio universal de comunicação, a linguagem, é ao mesmo tempo fisiológico, físico, psíquico e de domínio sociocultural (política, econômica, religião, artes, entre outros).

Com toda essa discussão explicitada, podemos indicar que houve, neste aspecto, um deslocamento na maneira de compreender o funcionamento da linguagem do primeiro para o segundo Wittgenstein ${ }^{9}$ : de uma concepção essencialista para uma concepção pragmática do significado da linguagem. Isto é, o uso depende das circunstâncias contextuais e não, apenas, de critérios lógicos universais. Moreno nos apresenta:

\footnotetext{
${ }^{9}$ Defendemos haver uma acentuada descontinuidade, no pensamento do primeiro e do segundo Wittgenstein, quando da passagem de uma rigorosa análise lógica dos limites da linguagem para uma concepção mais fluída e aberta, explorando os usos da linguagem em uma comunidade cultural (jogos de linguagem). No entanto, há uma coesão ao tomar a linguagem como a questão central de sua filosofia.
} 
Após o Tractatus, (...), o filósofo não mais considera a linguagem como uma entidade fixa da qual se pudesse exibir a essência através de um simbolismo formal. A linguagem passa a ser considerada como um caleidoscópio de situações de uso das palavras em que o contexto pragmático não pode ser mais eliminado. A palavra "linguagem" indica, a partir de então, um conjunto aberto de diferentes atividades envolvendo palavras, uma "família" de situações em que usamos palavras relativamente a circunstâncias extralinguísticas (MORENO, 1993, p. 15).

À vista disso, defendemos que esse deslocamento no modo de filosofar wittgensteiniano é animado por uma espécie de concepção antropológica onde as práticas dos seres humanos no cotidiano sustentam as relações internas dos significados e dos usos que fazemos da linguagem. É fundamental destacarmos que, a partir de elementos presentes na pragmática filosófica wittgensteiniana, os resultados daquilo que as pessoas dizem e compreendem por meio de uma interação e seus atos voluntários indicam a realidade coletiva da linguagem, bem como de seu processo de significação.

Para o Wittgenstein de Investigações, é o próprio uso das palavras nos diferentes contextos linguísticos e extralinguísticos que conferem significado à linguagem. É por meio deste esclarecimento que é possível entender os mecanismos que constituem a significação de uma expressão, quais elementos são levados em consideração neste processo (semântico) dos signos linguísticos e, consequentemente, como ele deve ser interpretado, compreendido. O filósofo irá nos apresenta que, "a significação de uma palavra é seu uso na linguagem” (IF, § 43), pois o que decide realmente sobre o sentido de uma palavra é seu uso efetivo.

Usar a linguagem consiste em uma atividade de mútuo envolvimento que se legitima e, ao mesmo tempo, se justifica por meio de um acordo estabelecido socialmente. Essa justificação que fundamenta nossas práticas discursivas está presente em todos os usos linguísticos que fazemos e é variável conforme o contexto. É notável, nessa perspectiva, que, mais do que veicular objetos, a linguagem transmite conteúdos culturais e a significação é um processo que se configura por meio de uma série de operações interdependentes, entre elas, a interação sociocultural dos sujeitos falantes.

A validação das práticas linguísticas só se torna uma realidade ao se indicarem as regras sob as quais algo é dito e feito, ao se tornarem explícitos os usos da linguagem, o contexto de pertencimento de tais usos e a função neles realizados. Pois, "a faculdade de estruturar linguagens se dá progressivamente pela aprendizagem e pela participação em um organismo social que dá suporte cultural à linguagem" (COSTA, L. S.; VALLE, B., 2013, 31).

Agora, contrariando aquela primeira perspectiva semântica que o filósofo adotara antes dos anos de 1930, que é uma doutrina sintática (teoria dos signos) da 
significação, o funcionamento da linguagem está no âmbito da atividade. Isto é, realiza-se nos contextos de ação e só pode ser compreendida a partir do horizonte contextual que está inserida. Estes contextos de ação são chamados, pelo filósofo, de formas de vida e a linguagem é sempre sua parte, seu constitutivo. Sua função, por isso, é relativa a ela, à qual integra-se no modo de interação dos homens, expressa por meio de uma práxis comunicativa interpessoal. Inúmeras são as formas de vida existentes, tantos são os contextos praxeológicos, múltiplos são os modos de uso da linguagem, ou, como Wittgenstein se expressa, tantos são os jogos de linguagem. Lemos em Investigações:

O termo "jogo de linguagem" deve aqui salientar que o falar da linguagem é uma parte de uma atividade ou de uma forma de vida.

Imagine a multiplicidade dos jogos de linguagem por meio destes exemplos e outros:

Comandar, e agir segundo comando -

Descrever um objeto conforme a aparência ou conforme medidas -

Produzir um objeto segundo uma descrição (desenho) -

Relatar um acontecimento -

Conjeturar sobre o acontecimento [...] (IF, § 23).

Com essa noção, o pensador exprime sua nova forma de interpretar o funcionamento da linguagem. Não há uma definição de jogo de linguagem - isso, segundo sua nova maneira de pensar, é impossível -, mas mostra o que pretende com tal categoria, partindo de exemplos situacionais.

Ao jogo de linguagem pertence: os elementos linguísticos, os sujeitos falantes e a situação linguística (forma de vida). A cena de uma construção (obra) em que alguém pede os objetos de construção a um auxiliar (Cf. IF, §2) é um dos tantos exemplos que Wittgenstein apresenta em seu texto para demonstrar os jogos de linguagem. $\mathrm{O}$ filósofo nos mostra que, nos diferentes contextos, seguem-se diferentes significações para as expressões linguísticas. Ora, assim sendo, a semântica só atinge sua finalidade, na segunda fase de seu pensamento, chegando à pragmática, pois seu problema central, o sentido das palavras e frases, só pode ser resolvido pela explicitação dos contextos pragmáticos.

Nesse processo todo, está envolvido o que Wittgenstein chama de seguimento de regra, um ato social que ocorre numa comunidade de vida por meio de hábitos e costumes, ou seja, é um processo de aquisição de determinada práxis de determinada comunidade humana. Como se pode notar, "seguir uma regra é análogo a: seguir uma ordem. Somos treinados para isto e reagimos de um determinado modo... O modo de agir comum a todos os homens é o sistema de referência, por meio do qual interpretamos uma linguagem” (IF, § 206). 
Num sentido prático, o acesso às regras, é uma condição de possibilidade da eficácia e da natureza cooperativa da linguagem. Tal situação é exigente, pois implica assumir a forma de vida da comunidade em questão. A significação das expressões vem da função que elas exercem nas diferentes formas de práxis humana. $\mathrm{O}$ autor enfatiza: "Todo signo sozinho parece morto. O que lhe dá vida? - No uso, ele vive" (IF, $\S 432$ ).

Contra todo essencialismo, o filósofo de Viena não precisa nunca o conceito de uso, como, aliás, nenhum outro conceito. A filosofia posterior a ele põe algum ordenamento em todas essas reflexões. O mérito do Wittgenstein da fase tardia está exatamente em ter aberto novas perspectivas para a consideração da linguagem humana, embora sua opção metodológica o tenha impedido de chegar a uma visão sistemática na investigação filosófica da linguagem do cotidiano.

A referência ao cotidiano como o espaço de significação da linguagem é uma das marcas do texto de Investigações Filosóficas. Este conjunto de elementos lança luz à possibilidade de discutir uma perspectiva antropológica na sua filosofia desenvolvida a partir da década de 30. Ao nos depararmos com o parágrafo, onde lemos: "o que fornecemos aqui são propriamente anotações sobre a história natural do homem" (IF §415), podemos considerar que uma perspectiva antropológica se evidencia. E é tomando a noção de jogo de linguagem como horizonte de significação das expressões que podemos refletir sobre essa questão.

Fisicamente, pensamos, a partir de Wittgenstein, que o uso do corpo nos permite reproduzir, por meio de uma aprendizagem, figuras de movimento com significação e memória que facultam aos sujeitos a possibilidade de dispor, compor, modificar e construir o mundo materialmente e culturalmente num espaço de ação. O corpo torna-se, portanto, eixo estrutural do espaço, localizando o homem nele.

Numa perspectiva antropológico-filosófica, a crítica do nosso autor, sinaliza o afastamento de um etnocentrismo que objetiva formatar apenas uma maneira de compreender os sujeitos, pois eles existem de diferentes modos e em diferentes contextos. Nesse sentido, podemos indicar que, suas considerações sobre a linguagem são tomadas a partir de uma perspectiva antropológica ao olhar para o homem em sua situação de cotidiano. As práticas dos sujeitos falantes em um contexto engendram uma visão antropológica e esta, por sua vez, é pensada a partir de sua filosofia da linguagem. Para Bassols, a partir de Investigações Filosóficas,

a análise wittgensteiniana da linguagem não é um estudo de linguística, nem sequer um estudo de antropologia linguística, é articular um estudo sobre as condições (biológicas, econômicas, físicas) do surgimento da linguagem ${ }^{10}$ (2011, p. 91).

\footnotetext{
${ }^{10}$ Tradução própria: “el examen wittgensteiniano del lenguaje no es un estudio de lingüística, ni siquiera un estudio de antropología lingüística, es decir un estudio sobre las condiciones (biológicas, econòmicas, físicas)
} 
A linguagem é, portanto, a nossa possibilidade de ação e de interação na comunidade e no mundo, pois constitui a realidade, a nossa compreensão e interpretação do contexto social que participamos. A reflexão antropológica que assumimos expõe um espírito de conjunto que enlaça nossas práticas linguísticas. A linguagem é, portanto, a nossa possibilidade de ação e de interação na comunidade e no mundo, pois constitui a realidade, a nossa compreensão e interpretação do contexto social que participamos.

\section{Considerações Finais}

Wittgenstein desenvolveu, sem dúvida, uma filosofia que deixou sua marca no pensamento do último século. As reflexões do filósofo vienense que produziram Investigações Filosóficas, por sua proximidade com elementos de ordem pragmática, são marcadas pela presença de notas antropológicas. É possível lançar inúmeras perspectivas em suas reflexões, tomando como elementos centrais as questões a respeito da significação da linguagem e o contexto.

$\mathrm{O}$ que deixamos entrever em nosso texto foi que a maneira antropológica abordada pelo nosso filósofo se deu a partir do seu retorno ao ordinário. Isto é, a partir do abandono de uma concepção essencialista para a concepção pragmática da linguagem, considerando os sujeitos, a linguagem e os seus usos. Este abando se deu, e esta é uma hipótese nossa, quando da percepção de que uma ontologia formal não sustentava integralmente os processos de significação da linguagem.

Nesse ínterim, o significado da linguagem é dado, então, por regras que inserem as palavras na vida dos sujeitos, permitindo, assim, que eles se relacionem com o mundo. A relação nós e o contexto, elemento fundamentalmente etnográfico, são preponderantes no processo de significação.

Nossos sentimentos, conceitos, emoções estão no emaranhado da vida cotidiana. Ao partilharmos da forma de vida esses elementos ganham uma regularidade em nosso intelecto. Tal regularidade se dá pelo nosso pertencimento cultural, pelas nossas relações e vínculos práticos estabelecidos no contexto. Há uma proximidade nas discussões que tentam pensar uma reflexão antropologia no pensamento tardio do autor e suas considerações sobre filosofia da psicologia ao pensar os conceitos psicológicos da experiência sensorial, cognitiva e afetiva. No entanto, esta é uma possibilidade a ser explorada em outra ocasião e com um aspecto mais vertical.

Afinal, Wittgenstein é um antropólogo? A resposta é não. O enfoque antropológico dado no texto de Investigações Filosóficas não resolve nenhuma questão científica sobre o que é antropologia. Os feitos antropológicos do ser humano são ações iluminadas e sustentadas por formas linguísticas carregadas de significados

del surgimiento del lenguaje".

Diaphonía, e-ISSN 2446-7413, v. 2, n. II, 2016 
dados em um contexto e legitimados pelos vínculos estabelecidos entre os sujeitos falantes.

\section{Referências bibliográficas}

BASSOLS, A. T. Wittgenstein: filosofía de la antropología y antropología filosófica. In: GÁLVEZ, J. P. (Ed.) Antropología de Wittgenstein: reflexionando con P. M. S. Hacker. Madrid: Plaza y Valdés Editores, Universidad de Castilla-La Macha, 2011.

COSTA, L. S.; VALLE, B., O Papel da dúvida na filosofia tardia de Ludwig Wittgenstein. Tabulae: Revista de Philosophia, Curitiba, v. 8, n. 15, jul-dez, 2013, p. 2534 .

MORENO, A. R. Wittgenstein, através das imagens. Campinas, SP: Editora da UNICAMP, 1993.

STEGMÜLLER, W. A filosofia contemporânea. Introdução crítica $2^{\underline{a}}$ ed. Rio de Janeiro: Forense Universitária, 2012.

WITTGENSTEIN, L. Investigações filosóficas. São Paulo: Abril Cultural, 1979. Tractatus logico-philosophicus. São Paulo: Edusp, 2008.

Submissão: 20.06.2016 / Aceite: 30.08.2016 